\title{
STATIC BALANCING OF ROBOT MECHANISMS AND MANIPULATION DEVICES
}

\author{
SEGLA Stefan ${ }^{1}$ \\ ${ }^{I}$ Technical University of Košice, Faculty of Mechanical Engineering, Department of Applied Mechanics and \\ Mechanical Engineering, Letná 9, 04200 Košice, Slovak Republic, email: stefan.segla@ tuke.sk
}

\begin{abstract}
The paper deals with static balancing of various kinds of mechanisms and manipulation devices using spring balancing mechanisms. In case of parallelogram robots and manipulation mechanisms a spring balancing mechanism exerting a constant force is used. Problems of static balancing of variable payloads are also presented and investigated in the paper. Static balancing is formulated as an optimization problem with the objective function expressing minimization of the forces acting in the driving joints. As design variables geometrical variables and spring stiffnesses and their unloaded lengths are used. Optimization Toolbox for Use with Matlab and GOOD (Generator Of Optimal Designs) are used to solve the static balancing problems. The optimized mechanisms are evaluated by using multibody dynamics programs taking into account friction effects in mechanism joints. The results of static balancing optimization show essential reduction of the gravity load in drive joints and consequently driving forces with important energy savings.
\end{abstract}

KEYWORDS: static balancing, static equilibrium, robot, mechanism, optimization

\section{Introduction}

The powered joints of robot mechanisms and manipulation devices are loaded by the gravity forces caused by the masses of the mechanism links and by mass of the payload. The masses of the mechanism links are often 10-15 times as large as the mass of the payload.

The balancing mechanisms should produce forces which make it possible to eliminate or at least substantially reduce the static gravity forces in the drive joints [1]. In this way also driving forces in the drive joints are substantially reduced. Two basic ways of static balancing exist in practice - static balancing by spring mechanisms and balancing by additional masses using counter-weights. Combination of these two ways is also possible and used. In some cases redistribution of links masses is possible. The balancing by spring mechanisms takes advantage of negligible changing the mass and inertia parameters of the balanced mechanisms.

Correctly formulated objective functions and appropriate choice of design (optimization) variables are of great importance for achieving good results $[2,8,9]$. Numerical optimization will be carried out by Optimization Toolbox for Use with Matlab [3] and optimization program GOOD [4]. It is possible to speed up numerical computation using the computer program Maple [5] for symbolic computation.

Evaluation of the optimally balanced mechanisms will be carried out by multibody dynamics programs SPACAR (Developed at TU Delft) and Working Model 2D [6]. Using other comercially available programs is also possible. 


\section{Static balancing of parallelogram robot mechanisms with spring mechanisms exerting constant force}

Parallelogram robot mechanisms have a special property. It is possible to find a point at which a force of constant magnitude can ideally balance the mechanism in its arbitrary position, Figs. 1 and 2. In [1] a special spring mechanism able to exert a force of the required constant magnitude and direction is presented, Fig. 3.

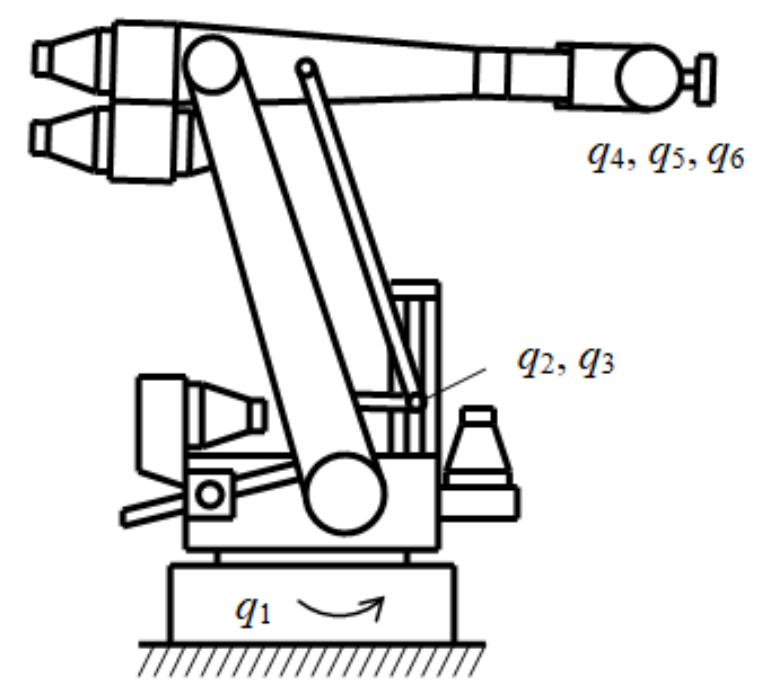

Fig. 1 Robot with parallelogram mechanism

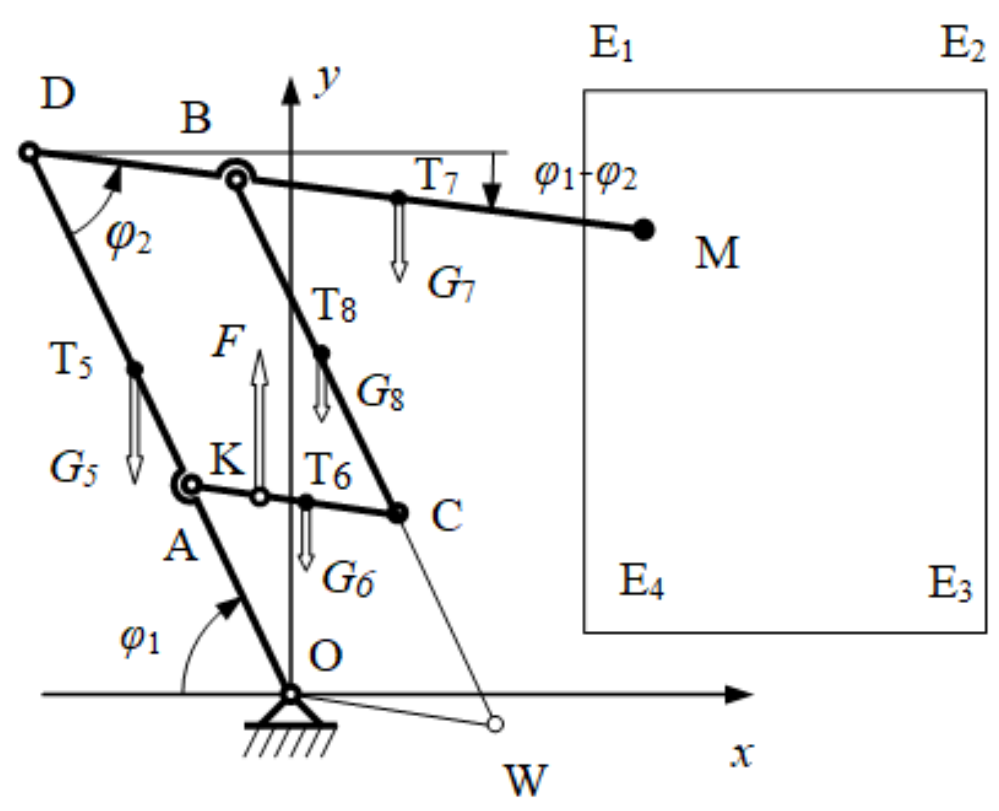

Fig. 2 Kinematic scheme of the robot with parallelogram mechanism 


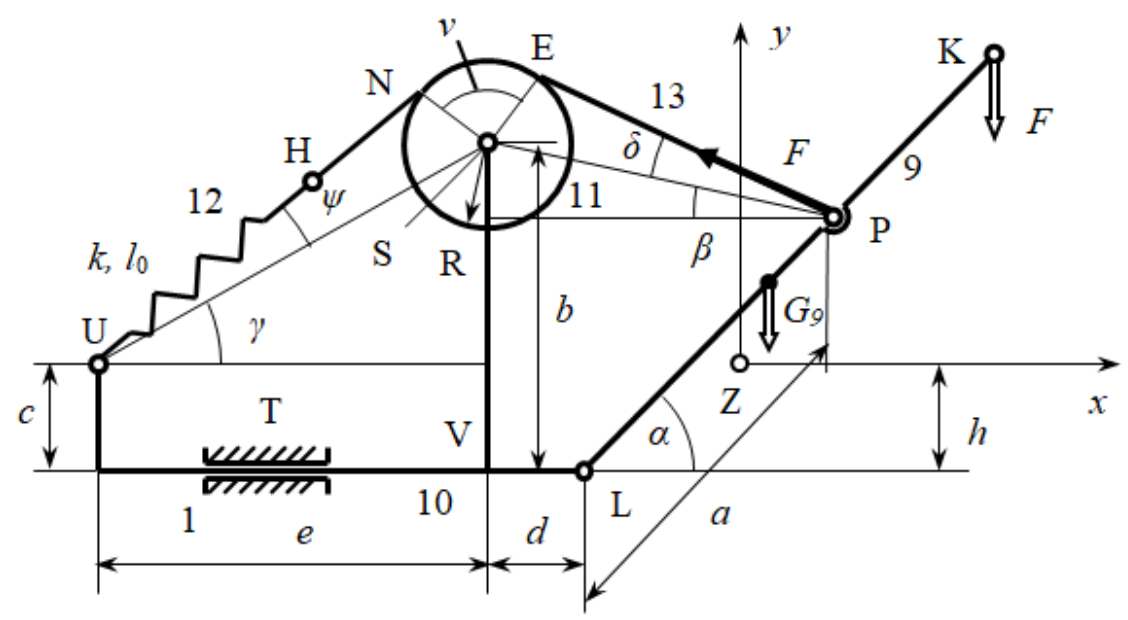

Fig. 3 Spring mechanism exerting constant force

For static balancing of the three transport degrees of fre .... m only two have to be balanced $-q_{2}$ and $q_{3}$, Fig. 1. The rotation about the vertical axis $\left(q_{1}\right)$ is balanced supposing that the robot is in vertical position. Balancing of three orientation degrees of freedom $\left(q_{4}, q_{5}, q_{6}\right)$ can usually be neglected. Equilibrium of static moments about point $\mathrm{O}$ is

$$
\begin{aligned}
& g \cos \varphi_{1}\left(m_{5} \overline{\mathrm{ZT}_{5}}+m_{7} l_{5}+m_{8} \overline{\mathrm{WT}_{8}}+m_{6} \overline{\mathrm{AZ}}\right)+g \cos \left(\varphi_{1}-\varphi_{2}\right) \\
& {\left[-m_{7} \overline{\mathrm{DT}_{7}}-m_{6} \overline{\mathrm{AT}_{6}}-m_{8} \overline{\mathrm{WZ}}\right]=F \overline{\mathrm{AZ}} \cos \varphi_{1}-F \overline{\mathrm{AK}} \cos \left(\varphi_{1}-\varphi_{2}\right)}
\end{aligned}
$$

where $F$ is the vertical balancing force at point K, Fig. 2.

Eq. (1) can be split into two equations by comparing terms multiplied by $\cos \varphi_{1}$ and $\cos \left(\varphi_{1}-\varphi_{2}\right)$

$$
g\left(m_{5} \overline{\mathrm{ZT}_{5}}+m_{7} l_{5}+m_{8} \overline{\mathrm{WT}_{8}}+m_{6} \overline{\mathrm{AZ}}\right)=F \overline{\mathrm{AZ}}
$$

and

$$
g\left(m_{7} \overline{\mathrm{DT}_{7}}-m_{6} \overline{\mathrm{AT}_{6}}-m_{8} \overline{\mathrm{WZ}}\right)=-F \overline{\mathrm{AK}}
$$

From eq. (2) the force for balancing the robot in arbitrary position determined by the coordinates $\varphi_{2}$ and $\varphi_{3}$ can be derived

$$
F=\frac{g\left(m_{5} \overline{\mathrm{ZT}_{5}}+m_{7} l_{5}+m_{8} \overline{\mathrm{WT}_{8}}+m_{6} \overline{\mathrm{AZ}}\right)}{\overline{\mathrm{AZ}}}
$$

Substituting $F$ into eq. (3) the position of point $\mathrm{K}$ can be determined

$$
\overline{\mathrm{AK}}=\overline{\mathrm{AZ}} \frac{\left(m_{7} \overline{\mathrm{DT}_{7}}+m_{6} \overline{\mathrm{AT}_{6}}+m_{8} \overline{\mathrm{WZ}}\right)}{\left(m_{5} \overline{\mathrm{ZT}_{5}}+m_{7} l_{5}+m_{8} \overline{\mathrm{WT}_{8}}+m_{6} \overline{\mathrm{AZ}}\right)}
$$

In the case of ideal spring balancing mechanism with massless link 9, Fig. 3, it would be able to exert the force $F$ needed for balancing the robot mechanism, eq. 4 . If the mass of the link 9 is taken into account, then the force exerted by the spring balancing mechanism can be derived from the moment equilibrium condition of the link 9 about point $\mathrm{L}$ in the form

$$
F^{\prime}=\frac{F_{\mathrm{P}} a \sin (\alpha+\beta+\delta)}{l_{9} \cos \alpha}-0.5 m_{9} g
$$




\subsection{Formulation of the optimization problem and results}

Minimization of the static loading in the transport degrees of freedom $\varphi_{2}$ and $\varphi_{3}$ can be formulated by the objective function in the form

$$
f_{\mathrm{op}}=\frac{1}{N} \sum_{i=1}^{N} \sqrt{\left(F-F_{i}^{\prime}\right)^{2}}
$$

which expresses minimization of the difference $\left(F-F^{\prime}\right)$ at $N$ points of the rectangular grid in the rectangle $\mathrm{E}_{1} \mathrm{E}_{2} \mathrm{E}_{3} \mathrm{E}_{4}$ in which the robot gripper $\mathrm{M}$ can move, Fig. 2.

As design variables were chosen: $k$ - the spring stiffness, $l_{0}$ - the length of the unloaded spring, $l_{9}$ - the length of the link 9 and geometrical dimensions $a, b, c, d$ and $e$. The length $l_{\mathrm{L}}$ of the rope HNEP, Fig. 3, is considered as so called computed variable for which the following condition holds

$$
l_{\mathrm{L}}=(\overline{\mathrm{NE}}+\overline{\mathrm{EP}})_{\max }+\overline{\mathrm{HN}}
$$

where the distance $\overline{\mathrm{HN}}$ is a specified variable (reserve). This condition does not allow the end point of the spring $\mathrm{H}$ to run over the puley in any position of the spring balancing mechanism.

Optimization was performed for the following specified variables: $m_{5}=57 \mathrm{~kg}, m_{6}=57 \mathrm{~kg}$, $m_{7}=57 \mathrm{~kg}, m_{8}=57 \mathrm{~kg}, m_{9}=57 \mathrm{~kg}, m_{\mathrm{M}}=10 \mathrm{~kg}$ (payload), $l_{5}=1.098 \mathrm{~m}, l_{6}=0.18 \mathrm{~m}, l_{7}=1.098$ $\mathrm{m}, l_{8}=0.918 \mathrm{~m}, \overline{\mathrm{ZT}_{5}}=0.5 \mathrm{~m}, \overline{\mathrm{WT}_{8}}=0.638 \mathrm{~m}, \overline{\mathrm{CT}_{8}}=0.458 \mathrm{~m}, \overline{\mathrm{AO}}=0.18 \mathrm{~m}, \overline{\mathrm{AT}_{6}}=0.09 \mathrm{~m}, h$ $=0.05 \mathrm{~m}$.

Using Optimization Toolbox for Use with Matlab the following optimal values of the design variables were obtained: $k_{\mathrm{opt}}=18929.02 \mathrm{~N} / \mathrm{m}, l_{0, \mathrm{opt}}=0.07 \mathrm{~m}, a_{\mathrm{opt}}=0.3031 \mathrm{~m}, b_{\mathrm{opt}}=$ $0.4268 \mathrm{~m}, R_{\mathrm{opt}}=0.0604 \mathrm{~m}, d_{\mathrm{opt}}=0.0477 \mathrm{~m}, c_{\mathrm{opt}}=0.0102 \mathrm{~m}, e_{\mathrm{opt}}=0.3626 \mathrm{~m}, l_{9, \mathrm{opt}}=0.3393$ $\mathrm{m}$.

Verification of the optimization results was carried out by computation of the balancing force at point $\mathrm{C}$ of the robot mechanism, Fig. 2. The average value of the balancing force is $F_{\mathrm{C}, \mathrm{av}}=0.04 \mathrm{~N}$.

Tab. 1 shows that different payloads deteriorate optimization results significantly (optimization was performed for $10 \mathrm{~kg}$ payload).

Tab. 1: Average balancing force $F_{\mathrm{C} \text {,av }}$ for varying payloads

\begin{tabular}{|c|l|}
\hline Payload $[\mathrm{kg}]$ & $F_{\mathrm{C}, \mathrm{av}}[\mathrm{N}]$ \\
\hline 0 & 474.59 \\
\hline 2 & 371.09 \\
\hline 4 & 272.52 \\
\hline 6 & 200.97 \\
\hline 8 & 87.24 \\
\hline 10 & 0.04 \\
\hline 12 & 83.36 \\
\hline 14 & 163.45 \\
\hline
\end{tabular}

Balancing different payloads can be improved by determining new optimum values of the parameter determining position of point $\mathrm{K}(\overline{\mathrm{AK}})$, at which the balancing force $F$ is acting, and by chosing an appropriate design variable (from the design point of view) and its reoptimization. As an appropriate design variable the parameter $b$ was chosen. The other design variables remain unchanged. Tab. 2 shows the results. 
Tab. 2: Optimum values of $\overline{\mathrm{AK}}$ and $b$

\begin{tabular}{|c|c|c|c|}
\hline Payload $[\mathrm{kg}]$ & $\overline{\mathrm{AK}}[\mathrm{m}]$ & $b_{\text {opt }}[\mathrm{m}]$ & $f_{\text {op }}[\mathrm{N}]$ \\
\hline 0 & 0.0167 & 0.4034 & 2.57 \\
\hline 2 & 0.0194 & 0.4082 & 2.12 \\
\hline 4 & 0.0221 & 0.4129 & 1.64 \\
\hline 6 & 0.0241 & 0.4173 & 1.07 \\
\hline 8 & 0.0271 & 0.4222 & 0.58 \\
\hline 10 & 0.0296 & 0.4268 & 0.005 \\
\hline 12 & 0.0319 & 0.4314 & 0.63 \\
\hline 14 & 0.0342 & 0.4359 & 1.29 \\
\hline
\end{tabular}

Tab. 3 presents the average balancing forces $F_{\mathrm{C} \text {,av }}$ for unbalanced robot with different payloads. These forces are too high which would negatively influence drive power and its frame size and also control accuracy.

Tab. 3: Average balancing force $F_{\mathrm{C} \text {,av }}$ of unbalanced robot

\begin{tabular}{|c|c|}
\hline Payload $[\mathrm{kg}]$ & $F_{\mathrm{C}, \mathrm{av}}[\mathrm{N}]$ \\
\hline 0 & 2645.98 \\
\hline 2 & 2682.46 \\
\hline 4 & 2735.65 \\
\hline 6 & 2770.56 \\
\hline 8 & 2829.14 \\
\hline 10 & 2876.42 \\
\hline 12 & 2923.49 \\
\hline 14 & 2970.24 \\
\hline
\end{tabular}

Computer simulations performed by multibody dynamics program Working Model 2D, Fig. 4, made possible evaluation of friction in mechanism joints A, B, C, D and O, Fig. 2. The friction moments are

$$
M_{\mathrm{f}}=\mu_{\mathrm{k}} L r
$$

where $\mu_{\mathrm{k}}$ is the coefficient of kinetic friction, $L$ is the joint load and $r$ is the shaft radius.

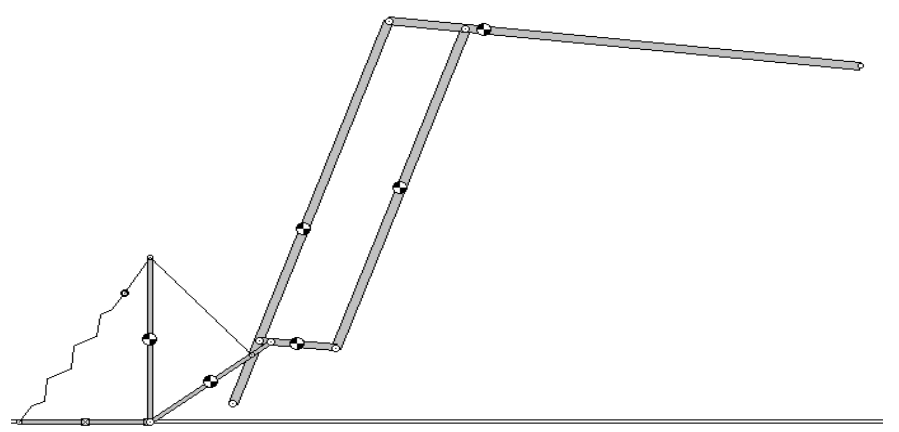

Fig. 4 Computer simulation of the robot mechanism in Working Model 2D

Figs. 5 and 6 present balancing forces $F_{\mathrm{Cx}}$ and $F_{\mathrm{Cy}}$ for very slow motion along the vertical in the working space of the robot $\left(0.3 \mathrm{~m}\right.$ to the right from the line $\mathrm{E}_{1} \mathrm{E}_{4}, \mathrm{Fig}$. 2). The figures show that friction does not significantly influence the results of static balancing optimization. 
The simulations were performed for four different kinetic friction coefficients $\left(\mu_{\mathrm{k}}=0\right.$ for case $\mathrm{A}, \mu_{\mathrm{k}}=0.001$ for case $\mathrm{B}, \mu_{\mathrm{k}}=0.002$ for case $\mathrm{C}, \mu_{\mathrm{k}}=0.003$ for case $\mathrm{D}$ ).

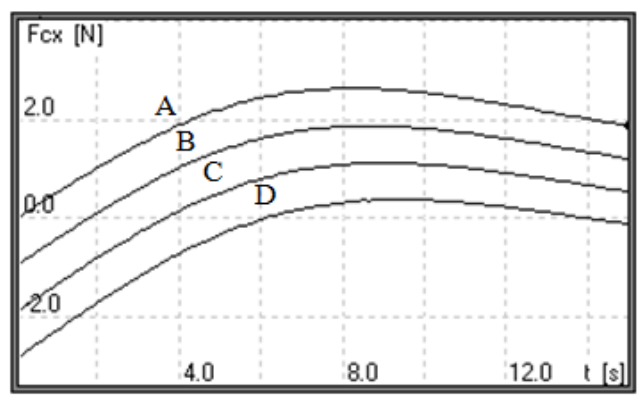

Fig. 5 Balancing force $F_{\mathrm{Cx}}$

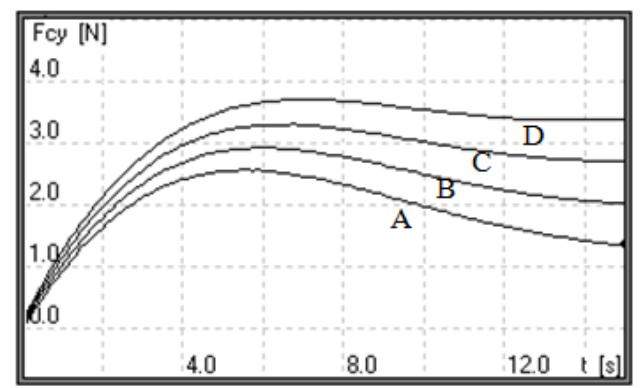

Fig. 6 Balancing force $F_{\mathrm{Cy}}$

\section{Static balancing of robot mechanisms with two spring balancing mechanisms}

For static balancing of of the transport degrees of freedom $\varphi_{2}$ and $\varphi_{3}$ of the robot mechanisms in Figs. 1 and 7 two spring mechanisms presented in Figs. 8 and 9 can be used [7].

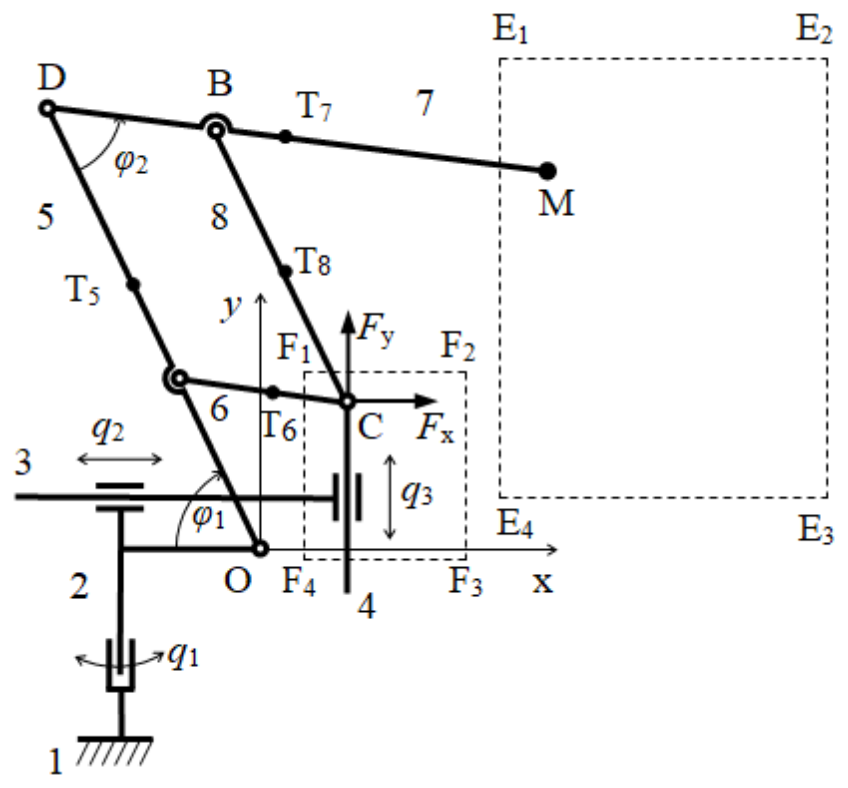

Fig. 7 Scheme of the robot mechanism 
The spring balancing mechanism in Fig. 8 is exerting the balancing force and this force is transmitted by means of two pullyes and a belt onto the link 7 (horizontal arm).

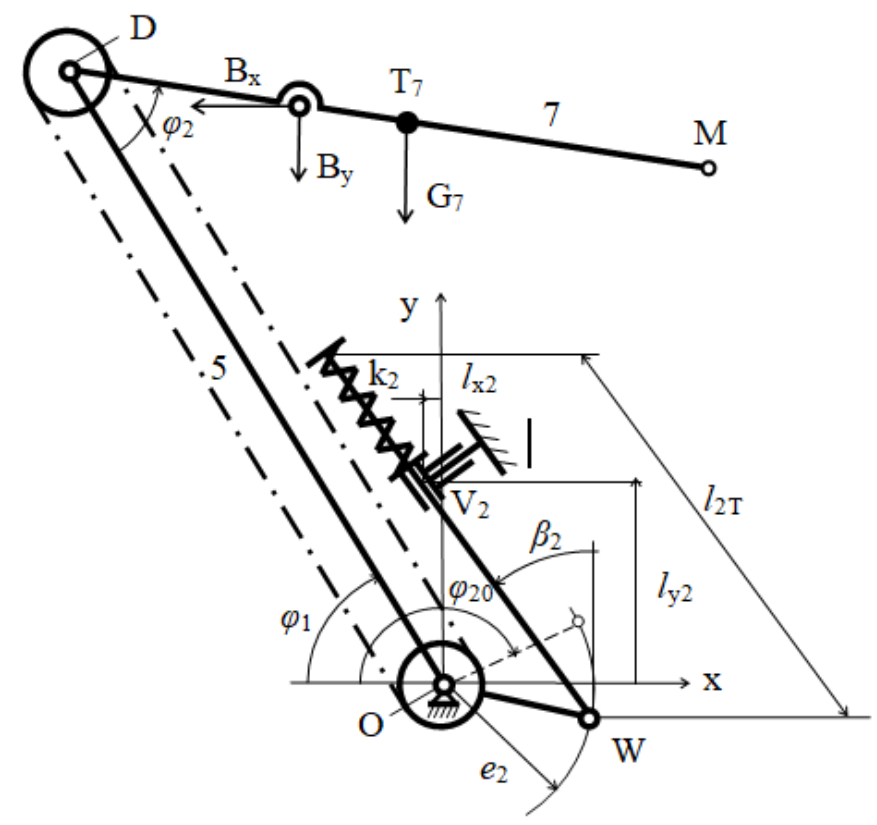

Fig. 8 Static balance of the link 7

Another spring balancing mechanism, Fig. 9, is exerting balancing force acting on the vertical arm 5 .

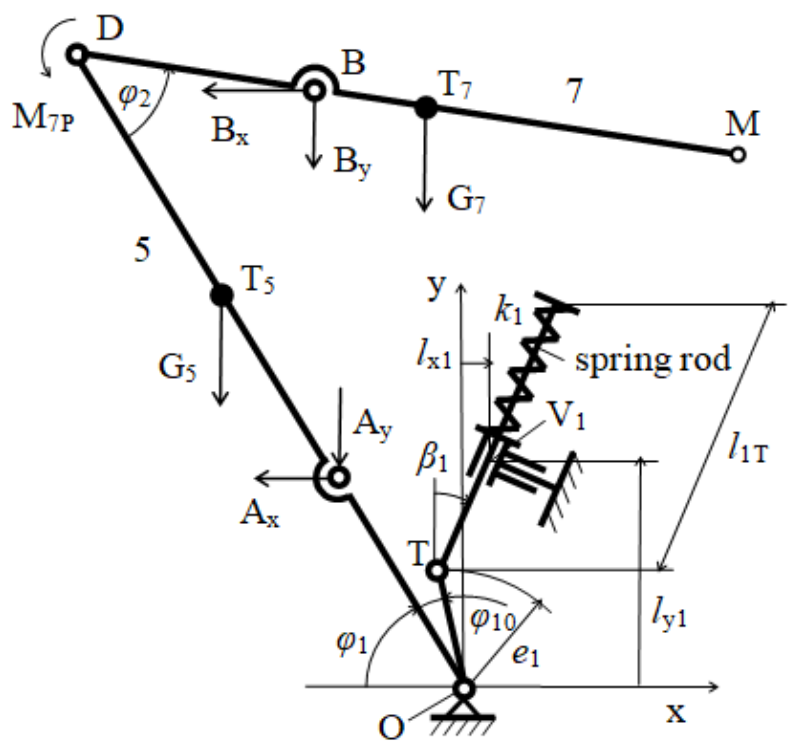

Fig. 9 Static balance of the links 5 and 7 together

From the static equilibrium conditions of the robot mechanism links in Fig. 7 the equilibrium conditions for 6 unknowns can be derived in the form 


$$
\left[\begin{array}{cccccc}
1 & 0 & 1 & 0 & 1 & 0 \\
0 & 1 & 0 & 1 & 0 & 1 \\
0 & 0 & 0 & 0 & s v & c v \\
0 & 0 & s f 1 & c f 1 & 0 & 0 \\
0 & 0 & s v & c v & 0 & 0 \\
s f 1 & c f 1 & 0 & 0 & 0 & 0
\end{array}\right]\left[\begin{array}{c}
A_{\mathrm{x}} \\
A_{\mathrm{y}} \\
B_{\mathrm{x}} \\
B_{\mathrm{y}} \\
F_{\mathrm{x}} \\
F_{\mathrm{y}}
\end{array}\right]=\left[\begin{array}{c}
0 \\
A \\
B \\
C \\
D \\
E
\end{array}\right]
$$

where: $c v=\cos \left(\varphi_{1}-\varphi_{2}\right), s v=\sin \left(\varphi_{1}-\varphi_{2}\right), s f 1=\sin \varphi_{1}, c f 1=\cos \varphi_{1}, s f 2=\sin \varphi_{2} q=\overline{\mathrm{AT}_{6}}, \mathrm{p}$ $=\overline{\mathrm{ZT}_{5}}$ and

$$
\begin{aligned}
& A=G_{6}+G_{8}, \quad B=\left(l_{6} c v G_{8}+q c v G_{6}\right) / l_{6}-\left(M_{7 P}-d c v G_{7}\right) / b, \\
& C=c c f 1 G_{8} / l_{8}, \quad D=\left(M_{7 P}-d c v G_{7}\right) / b, \\
& E=\left(-l_{5} c f 1 G_{7}-M_{5 P}-p c f 1 G_{5}-\left(l_{5} c c f 1 G_{8} / l_{8}\right)\right) / a
\end{aligned}
$$

The balancing forces $F_{\mathrm{x}}$ and $F_{\mathrm{y}}$ acting at point C, Fig. 7, are determined using Maple in the form

$$
\begin{gathered}
F_{x}=c f 1 c v\left[-G_{5} p / a+G_{6}+M_{5 P} /(c f 1 a)+l_{5} G_{7} / a-G_{6} q / l_{6}-G_{8} c / l_{8}-\right. \\
\left.-G_{7} d / b+M_{7 P} /(c v b)+l_{5} G_{8} c /\left(a l_{8}\right)\right] / s f 2 \\
F_{y}=c f 1 s v\left[-l_{5} c G_{8} /\left(a l_{8}\right)+G_{8} c / l_{8}-l_{5} G_{7} / a-G_{5} p / a-\right. \\
\left.-M_{5 P} /(c f 1 a)-G_{6}\right] / s f 2+s f 1 c v\left[-M_{7 P} /(b c v)+G_{7} d / b+G_{6} q / l_{6}\right] / s f 2+G_{8}
\end{gathered}
$$

The following parameters were chosen as design variables (see Figs. 8 and 9): $k_{1}-$ the spring stiffness, $l_{01}$ - the length of the unloaded spring $k_{1}, e_{1}, l_{\mathrm{x} 1}, l_{\mathrm{x} 2}$ - position of the rotational-translational joint $\mathrm{V}_{1}, \varphi_{10}$ - the angle determining the position of point $\mathrm{T}, k_{2}, l_{02}, e_{2}$, $l_{\mathrm{y} 1}, l_{\mathrm{y} 2}-$ variables analogical to the variables for the first spring mechanism, $\varphi_{20}-$ the angle determining the position of point $\mathrm{T}$ for $\varphi_{1}=\varphi_{2}$.

The objective function expressing the average balancing force at point $\mathrm{C}$, Fig. 7, can be defined in the form

$$
f_{\mathrm{op}}=\frac{1}{N} \sum_{i=1}^{N} \sqrt{{F_{x i}{ }^{2}+F_{y i}^{2}}^{2}}
$$

where $F_{x i}$ and $F_{y i}$ are components of the resultant balancing force at point $\mathrm{C}$ which are computed at points of an rectangular grid of the rectangle $\mathrm{F}_{1} \mathrm{~F}_{2} \mathrm{~F}_{3} \mathrm{~F}_{4}$ in which point $\mathrm{C}$ can move (motion of point $\mathrm{C}$ corresponds to motion of the gripper $\mathrm{M}$ in the robot working space $\mathrm{E}_{1} \mathrm{E}_{2} \mathrm{E}_{3} \mathrm{E}_{4}$, Fig. 7).

For the specified mass and geometric variables, given in section 2.1 , the output of the optimization program GOOD is: $f_{\mathrm{op}}=3.15 \mathrm{~N}$. The balancing force at point $\mathrm{C}$ is presented in Fig. 10 at the points of the rectangular grid in the rectangle $\mathrm{F}_{1} \mathrm{~F}_{2} \mathrm{~F}_{3} \mathrm{~F}_{4}$ determined by the coordinates $x$ and $y$, Fig. 7.

The average value of the balancing force at point $\mathrm{C}$ was verified by the multibody dynamics program SPACAR for the optimum values of the design variables. The average value was found to be $3.46 \mathrm{~N}$. 


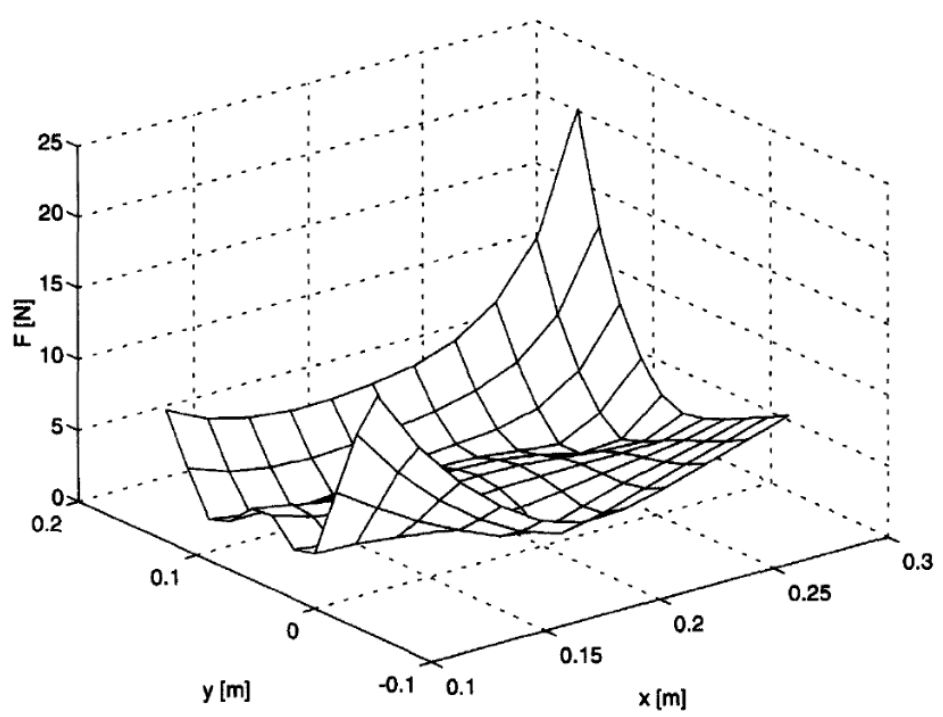

Fig. 10 Balancing force as function of position of point $\mathrm{C}$

\section{$4 \quad$ Balancing of bed upright positioning}

In health care various mechanisms are used for positioning patients in medical investigations and procedures.

In this section optimization of statical balancing of an verticalization bed equipped with a spring balancing mechanism will be described.

Mechanical model of the verticalization is presented in Fig. 11.

The spring balancing mechanism consists of the spring rod 3, spring 5 and rotationaltranslational joint $\mathrm{C}$. The balancing force exerted by this balancing mechanism is acting on the bed in joint $\mathrm{B}$.

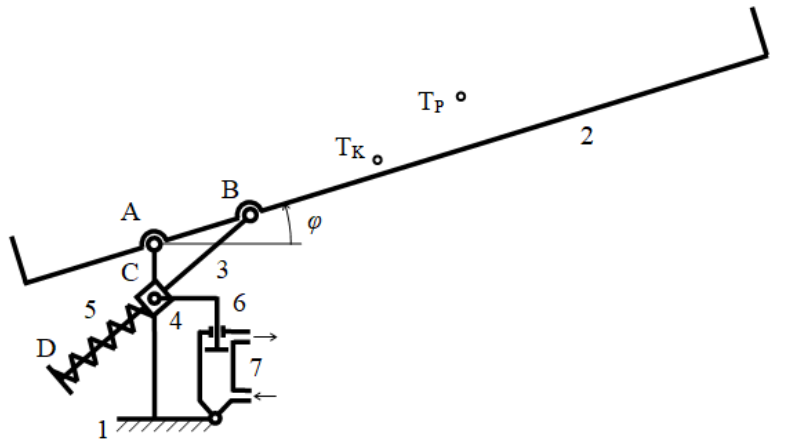

Fig. 11 Mechanical model of the verticalization bed

Static equilibrium conditions of the spring rod 3 and bed 2, Figs. 12 and 13, enable us to determine the fictitious force $F$ needed to balance the mechanism at a position determined by the angle $\varphi$. 


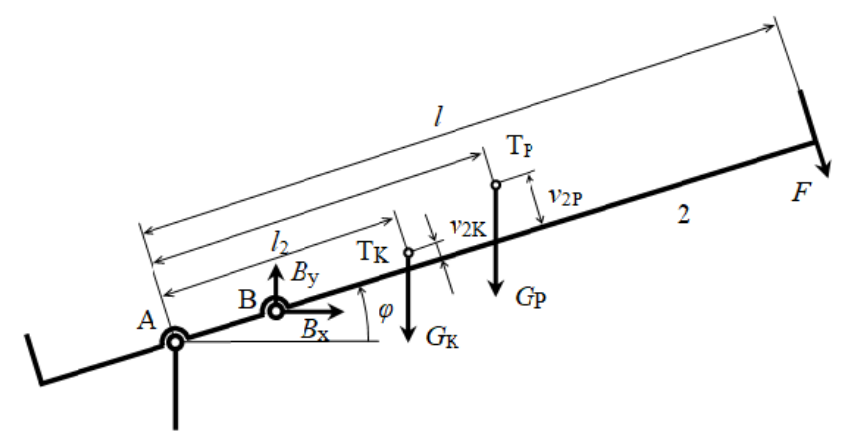

Fig. 12 Free-body diagram of the bed 2

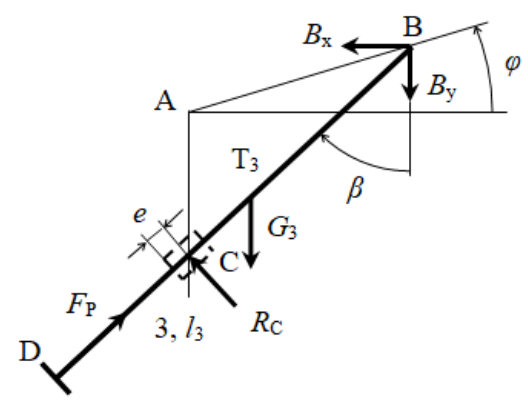

Fig. 13 Free-body diagram of the spring rod

The fictitious force $F$ is used to formulate the objective function

$$
f_{\mathrm{op}}=\frac{1}{N} \sum_{i=1}^{N} \sqrt{F_{i}^{2}}
$$

where $N$ is the number of positions $\varphi_{i} \in\left\langle 0^{\circ}, 90^{\circ}\right\rangle$ in which the force $F$ is evaluated.

As optimization variables the following variables were chosen: $k$ - the spring stiffness, $l_{0}-$ the length of the unloaded spring $k_{1}, l_{3}$ - the length of the spring rod $3, l_{\mathrm{AB}}$ and $l_{\mathrm{AC}}-$ distances of joints $\overline{\mathrm{AB}}$ and $\overline{\mathrm{AC}}$.

The following variables are specified (see Figs. 12 and 13): $l_{2}=1.8 \mathrm{~m}, l_{2 \mathrm{P}}=1.1 \mathrm{~m}$ and $v_{2 \mathrm{P}}$ $=1.8 \mathrm{~m}$ determine the mass center of the patient, $l_{2 \mathrm{~K}}=0.85 \mathrm{~m}$ and $v_{2 \mathrm{~K}}=0.035 \mathrm{~m}$ determine the mass center of the bed $2, m_{\mathrm{P}}=80 \mathrm{~kg}$ (mass of the patient), $m_{\mathrm{K}}=37.5 \mathrm{~kg}$ (mass of the bed).

Using Optimization Toolbox for Use with Matlab the following optimal values of the of the design variables were found: $k_{\mathrm{opt}}=44987,56 \mathrm{~N} / \mathrm{m} ; l_{0, \mathrm{opt}}=0,1210 \mathrm{~m} ; l_{3, \mathrm{opt}}=1,0877 \mathrm{~m}$; $l_{\mathrm{AB}, \mathrm{opt}}=0,45 \mathrm{~m} ; l_{\mathrm{AC}, \mathrm{opt}}=0,06 \mathrm{~m}$. The value of the objective function is $f_{\mathrm{op}}=24.75 \mathrm{~N}$.

Fig. 14 shows dependence of the fictitious force $F$ on the angle $\varphi$ determining position of the bed for several different masses of the patient 


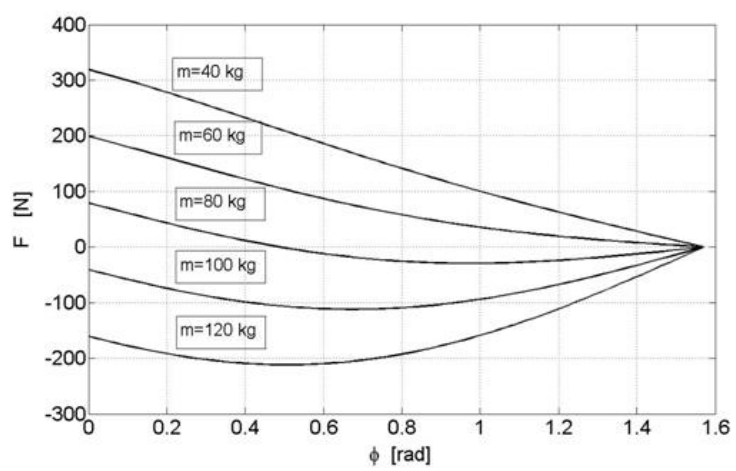

Fig. 14 Fictitious balancing force $F_{\mathrm{V}}$

Tab. 4 shows the values of the objective function $f_{\mathrm{op}}$ with and without additional optimization where the only optimization variable $l_{\mathrm{AC}}$ was chosen. The results show significant improvement of the statical balancing.

Tab. 4: Objective function value with and without additional optimization

\begin{tabular}{|c|c|c|c|}
\hline $\begin{array}{c}\text { Patient mass } \\
m_{\mathrm{P}}[\mathrm{kg}]\end{array}$ & $\begin{array}{c}\text { Optimum } \\
\text { value of } \\
l_{\mathrm{AC}}[\mathrm{m}]\end{array}$ & $\begin{array}{c}\text { Objective function } \\
\text { with additional } \\
\text { optimization } f_{\mathrm{op}}[\mathrm{N}]\end{array}$ & $\begin{array}{c}\text { Objective function } \\
\text { without additional } \\
\text { optimization } f_{\mathrm{op}}[\mathrm{N}]\end{array}$ \\
\hline 40 & 0,0358 & 9,65 & 151,12 \\
\hline 60 & 0,0473 & 16,23 & 75,0 \\
\hline 80 & 0,06 & 24,75 & 24,75 \\
\hline 100 & 0,0722 & 34,94 & 77,25 \\
\hline 120 & 0,0857 & 47,29 & 153,37 \\
\hline
\end{tabular}

Fig. 15 presents dependence of the fictitious balancing force $F$ on the angle $\varphi$ for several different masses of the patient after additional optimization.

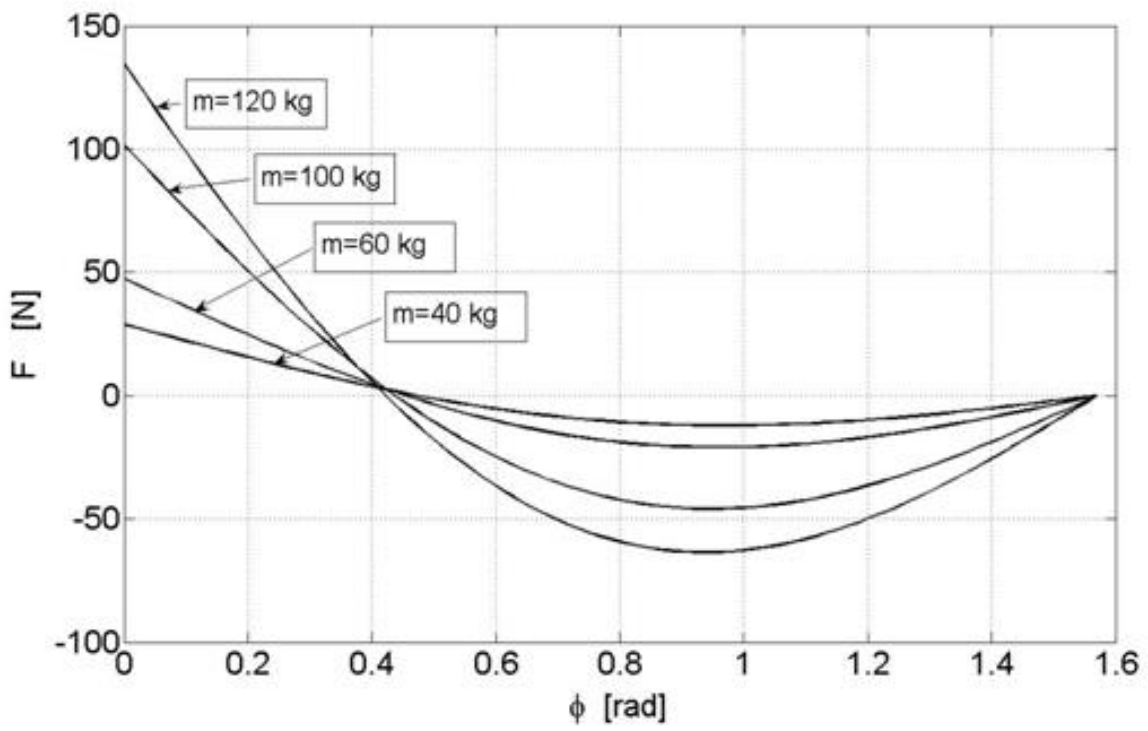

Fig. 15 Fictitious balancing force $F$ after additional optimization 


\section{$4 \quad$ Hydraulic scissor lift}

Fig. 16 shows mechanical model of an hydraulic double scissor lift. For energy saving a spring balancing mechanism is used which makes possible adjusting for different loadings. The mechanical model consists of arms 2 to 5, a table 6, rotational joints A, C, D, E, F, G and rotational-translational joints $\mathrm{B}$ and $\mathrm{H}$. The table is loaded with gravitational force $G_{\mathrm{Z}}$. Gravitational forces of all arms 2 to 5 acting at their centroids are also taken into account. Friction at all joints is not considered.

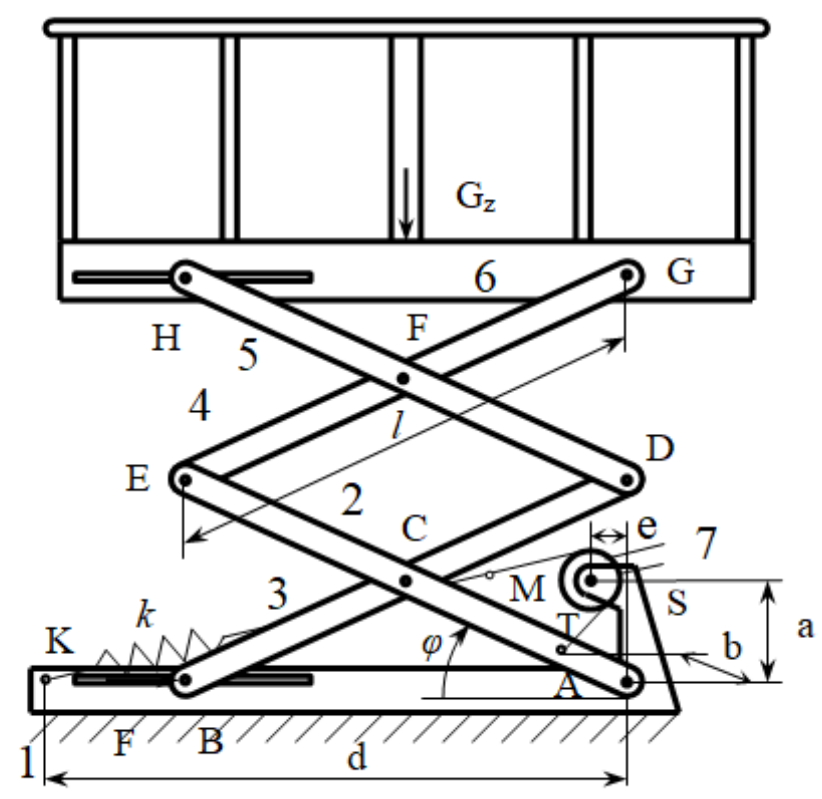

Fig. 16 Mechanical model of the hydraulic double scissor lift

The balancing mechanism consists of the puley 7, spring of constant stiffness $k$ and unloaded length $l_{0}$ and the rope MT.

Equations of static equilibrium in the matrix form are

$$
\mathbf{A x}=\mathbf{b}
$$

The vector of unknowns $\mathbf{x}$ includes not only reactions in joints but also the balancing force $F$, Fig. 16, exerted by an hydraulic drive placed horizontally between point B and the frame 1 .

The objective function can be written in the form

$$
f_{\mathrm{op}}=\frac{1}{N} \sum_{i=1}^{N} \sqrt{F_{i}^{2}}
$$

expressing minimization of the average balancing force $F$ for $\varphi \in\left\langle\varphi_{\min }, \varphi_{\max }\right\rangle$.

As design variables are considered: $k$ - the spring stiffness, $l_{0}-$ the length of the unloaded spring and $a, b$ and $c$ are geometrical parameters, Fig. 16. The length of the rope MT is considered as an computed variable and in this way preventing the rope from winding over the puley.

The specified parameters are: $m_{2}=m_{3}=m_{4}=m_{5}=33 \mathrm{~kg}, m_{6}=108 \mathrm{~kg}, m_{\mathrm{Z}}=180 \mathrm{~kg}$ (two persons on the table 6), $l=2.2 \mathrm{~m}, r=0.04 \mathrm{~m}$ (puley radius), $d=2.4 \mathrm{~m}, \varphi_{\min }=7^{\circ}, \varphi_{\max }=45^{\circ}$. 
The value of the objective function after optimization is $f_{\mathrm{op}}=5.13 \mathrm{~N}$. Fig. 17 shows the balancing force $F$ in the specified motion interval $\varphi \in\left\langle\varphi_{\min }, \varphi_{\max }\right\rangle$.

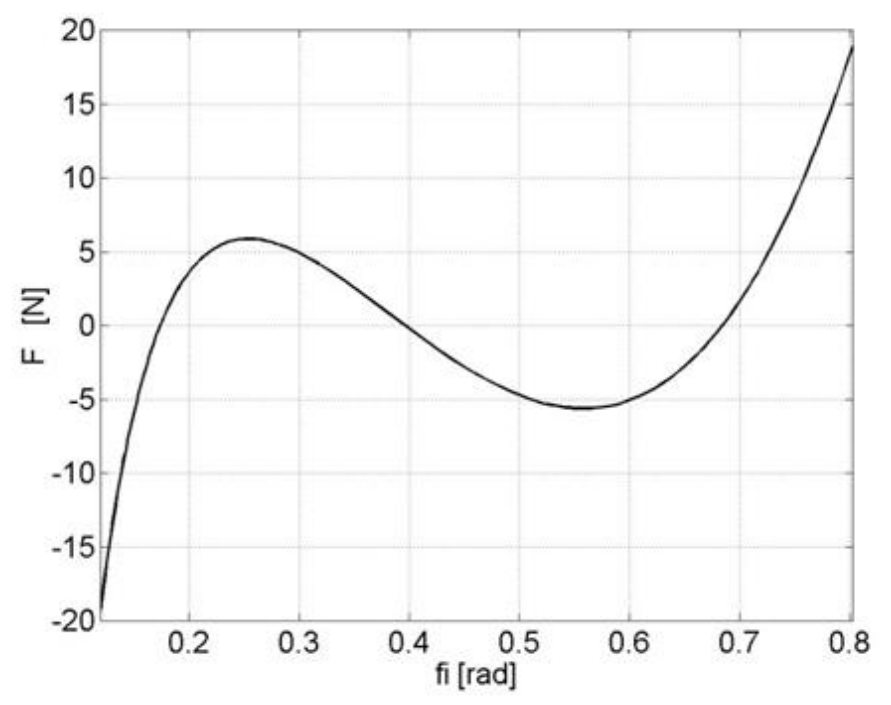

Fig. 17 Balancing force $F$ for $m_{\mathrm{Z}}=160 \mathrm{~kg}$

Additional optimization for the changed loading $m_{\mathrm{Z}}=80 \mathrm{~kg}$ was performed for one chosen design variable $e$. Its optimum value is $e_{\mathrm{opt}}=0.151 \mathrm{~m}$ (after the first optimization was $e=$ $0.172 \mathrm{~m})$. The other design variables remain unchanged.

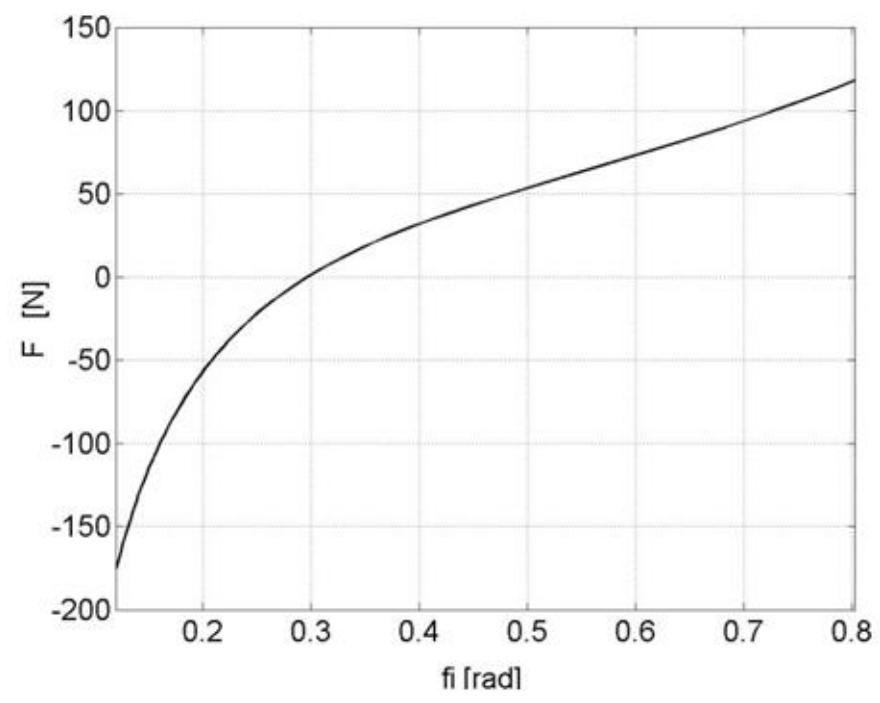

Fig. 18 Balancing force $F$ for $m_{\mathrm{Z}}=80 \mathrm{~kg}$

\section{CONCLUSION}

The paper shows that the problem of static balancing of robot mechanisms and manipulation devices with spring balancing mechanisms can be formulated as an optimization problem. For its numerical solution various optimization programs can be used.

Balancing forces can be derived with the aid of a Computer Algebra System (e.g. Maple) in a symbolic form leading to faster computations. 
The optimized mechanisms can be evaluated with multibody dynamics programs with a possibility to compute various kinematic and force variables taking into account real designs of mechanism links.

The spring balancing mechanisms usually offer a simple possibility to adjust one chosen design variable and reoptimize its value for different loadings of the mechanism while the other design variables remain unchanged.

\section{ACKNOWLEDGEMENTS}

This work was supported by the grant project VEGA No. 1/0731/16.

\section{REFERENCES}

[1] A.I. Korendasev et al. Manipulation systems of robots (in Russian). Mashinostrojenije, Moscow, 1989.

[2] C.M. Kalker-Kalkman. A general multi-objective optimization program for mixed continuous/integer variables based on Genetic Algorithms. In: Brøns M., Bendsøe M.P., Sørensen M.P. (eds) Progress in Industrial Mathematics at ECMI 96. European Consortium for Mathematics in Industry, vol. 9. Vieweg+Teubner Verlag, Wiesbaden, ISBN 978-3-322-96689-6, DOI:10.1007/978-3-322-96688-9_40, 1997.

[3] Optimization Toolbox for Use with Matlab - Users Guide. Version 2. The MathWorks Inc., Natick, USA, 1999.

[4] C.M. Kalker-Kalkman. Advances in computer-aided engineering. Delft University Press, Delft, 1994, 61-70, ISBN 90-407-1017-1.

[5] Maple 5.3. University of Waterloo, Ontario, Canada,1996.

[6] Working Model ${ }^{\circledR}$ 2D, Version 4.0, User's Manual, Knowledge Revolution, San Mateo, USA, 1996.

[7] S. Segla, C.M. Kalker-Kalkman, A.L. Schwab. Statical balancing of a robot mechanism with the aid of a Genetic Algorithm. Mech. Mach. Theory 1998 (33), No. 1-2, 163 174.

[8] A. Shala, M. Bruci. Proposed robot scheme with 5 DOF and dynamic modelling using MAPLE software, Journal of Mechanical Engineering - Strojnicky časopis 2017 (67), No. 2, 101-108.

[9] H. Štekbauer, I. Němec. A new cable-pulley algorithm in RFEM, Journal of Mechanical Engineering - Strojnícky časopis 2016 (66), No. 2, 89 - 94. 